\title{
Phenotype commitment in vascular smooth muscle cells derived from coronary atherosclerotic plaques: differential gene expression of endothelial Nitric Oxide Synthase
}

\author{
M. L. Rossi, ${ }^{\text {a† }}$ N. Marziliano, ${ }^{\text {b }}$ P. A. Merlini, ${ }^{\mathrm{c}}$ Ezio Bramucci, ${ }^{\mathrm{d}}$ U. Canosi, ${ }^{\mathrm{d}}$ P. Presbitero, ${ }^{\mathrm{a}}$ \\ E. Arbustinie, P. M. Mannuccif, D. Ardissinog
}

"Istituto Clinico “Humanitas", Unità Operativa di Emodinamica e Cardiologia Interventistica, Rozzano

(Milan) Italy; 'Molecular Biology Core Lab, Applera Italia, Monza (Milan) Italy; 'IV Division of Cardiology, Ospedale Niguarda (Milan) Italy, 'Department of Cardiology, IRCCS Policlinico S. Matteo Pavia, Italy; 'Molecular Diagnostics, Cardiovascular and Transplant Pathology Laboratory, Transplant Research Area, IRCCS Policlinico S. Matteo Pavia, Italy; 'Haemophylia and Thrombosis Center, Department of Internal Medicine, University of Milan, Italy; ' Division of Cardiology, Ospedale Maggiore, Parma), Italy;

'Both authors equally contributed to this article

(C)2005, European Journal of Histochemistry

Unstable angina and myocardial infarction are the clinical manifestations of the abrupt thrombotic occlusion of an epicardial coronary artery as a result of spontaneous atherosclerotic plaque rupture or fissuring, and the exposure of highly thrombogenic material to blood. It has been demonstrated that the proliferation of vascular smooth muscle cells (VSMCs) and impaired bioavailabilty of nitric oxide (NO) are among the most important mechanisms involved in the progression of atherosclerosis. It has also been suggested that a NO imbalance in coronary arteries may be involved in myocardial ischemia as a result of vasomotor dysfunction triggering plaque rupture and the thrombotic response. We used 5' nuclease assays (TaqMan ${ }^{\mathrm{TM}}$ PCRs) to study gene expression in coronary plaques collected by means of therapeutic directional coronary atherectomy from 15 patients with stable angina (SA) and 15 with acute coronary syndromes (ACS) without ST elevation. Total RNA was extracted from the 30 plaques and the cDNA was amplified in order to determine endothelial nitric oxide synthase (eNOS) gene expression. Analysis of the results showed that the expression of eNOS was significantly higher $(p<0.001)$ in the plaques from the ACS patients. Furthermore, isolated VSMCs from ACS and SA plaques confirmed the above pattern even after 25 plating passages. In situ RT-PCR was also carried out to co-localize the eNOS messengers and the VSMC phenotype.

The eNOS gene was more expressed in ACS plaques and VSMCs cultured from them, thus indicating that: a) the expression of the most important differentiation markers is retained under in vitro conditions; and b) NO may play a pivotal role in coronary artery disease. Our findings suggest a new cell system model for studying the pathophysiology of unstable angina and myocardial infarction.

Key words: Atherosclerosis; stable angina; acute coronary syndromes without ST elevation; gene expression; 5' nuclease (TaqMan ${ }^{\mathrm{TM}}$ ) assay; eNOS; immunohistochemistry

Correspondence: Marco L Rossi, MD Istituto Clinico "Humanitas", Unità Operativa di Emodinamica e Cardiologia Interventistica, Rozzano via Manzoni 56-20089-RozzanoMilano, Italy Tel. +393389373048 Fax +390398389497

E-mail: marcolrossi@hotmail.com

Paper accepted on ???? ?, 2005
C oronary thrombosis is a well-known process arising from plaque rupture or erosion. Plaque destabilisation and rupture are responsible for the majority of acute coronary events, including unstable angina, acute myocardial infarction and sudden coronary death (Davies and Thomas, 1985; Fuster et al., 1992; Leach et al., 1995; Richardson et al., 1989; Cheng et al., 1993). Nitric oxide (NO) is the key endothelium-derived relaxing factor that plays a central role in regulating vasomotor function and vascular tone (Moncada and Higgs, 2002). Various data indicate a close link between arterial inflammation, atherosclerotic disease (Van der Wal et al., 1994; Kohchi et al., 1985) and an imbalanced production or availability of NO. In addition to its vasodilatory effect, NO protects against vascular injury; it has been demonstrated that during the development of atherosclerosis, reduced intracellular concentrations of NO promote leukocyte adhesion to the endothelium, platelet aggregation, and changes in the biological characteristics of endothelial cells triggered by LOX-1, P-selectin, VCAM and ICAM-1 enhanced expression (Gauthier et al., 1995; de Graaf et al., 1992; Szmitko et al., 2003). These endothelial modifications lead to the progression of atherosclerosis within coronary vessels.

The migration and proliferation of vascular smooth muscle cells (VSMCs) in the arterial intima are key events in the development of atherosclerosis (Bochaton-Piallat et al., 1996), and so alterations in VSMC behaviour and characteristics may contribute to vascular pathophysiology. At least two distinct VSMC phenotypes are present in the vessel 
wall (Frid et al., 1994; Ko et al., 199; Mosse et al., 1985): the so-called contractile or differentiated VSMC phenotype, which is more abundant in healthy blood vessels, and a non-contractile or synthetic phenotype, particularly represented in areas of intense vascular remodelling such as the initial atherosclerotic lesions (Kuro-o et al., 1991; Rocnik et al., 2001; Owens et al., 1995). In VSMCs with the latter phenotype (so-called dedifferentiated VSMCs), the expression of proteins regulating contractile function (e.g. the smooth muscle-specific isoform of myosin, alpha-actin and calponin) is decreased, and the ability to generate extracellular matrix is increased (Trovati et al., 1999; Luoma et al., 1998). The process by which VSMCs change from a quiescent state to an activated proliferative and migratory phenotype (Trovati et al., 1999) is called phenotypic modulation, and is the hallmark of atherosclerosis.

Furthermore, although endothelial cells are by far the main site of vascular NO synthesis, VSMCs also express nitric oxide synthases (NOSs), which may be important in vessel function (Papapetropoulos et al., 1999). However, little is known about the expression of constitutive NOS in VSMCs or its modulation in ex vivo atherosclerotic plaques.

A large number of histological and in situ mRNA hybridisation (ISH) studies of coronary atherectomy material post mortem have shown that there are considerable overlaps between the inflammatory infiltrates in the plaques harvested from patients with stable or unstable angina. However, the systemic levels of inflammatory markers are somewhat lower in patients with stable angina than in those with acute coronary syndromes (Moncada and Higgs, 1993).

We here report the results of a study of the expression of the eNOS gene in atherosclerotic plaques obtained from the coronary arteries of patients with stable angina or acute coronary syndromes by means of directional coronary atherectomy. We used the $5^{\prime}$ nuclease assay (Livak and Schmittgen, 2001) for gene expression profiling and in situ RT-PCR to confirm VSMC co-localisation of the mRNAs. We also performed these two assays using VSMCs cultured from the plaques in order to investigate their cell commitment and behaviour.

\section{Materials and Methods}

\section{Patients}

The study involved 15 patients with stable angina (SA: Canadian Cardiovascular Society classes IIII) and 15 with acute coronary syndromes (ACS) without ST segment elevation, who underwent directional coronary atherectomy (DCA) for a single de novo lesion. Patients were excluded if they had multivessel coronary artery disease, which was defined as visually assessed $>70 \%$ diameter stenoses in more than one major coronary artery. All of the enrolled patients gave their informed consent and the study was approved by the Ethics Committee of Policlinico San Matteo.

Selective coronary arteriography was performed in multiple views using Judkins' technique. The coronary lesions underwen DCA using standard clinical procedures. Briefly, after a $300 \mathrm{~cm}$ guidewire had been passed through the lesion, the atherectomy device was positioned across the stenosis, and the support balloon inflated to $1 \mathrm{~atm}$. The cutter was then retracted and the balloon inflation pressure increased to a maximum of $3 \mathrm{~atm}$. The driving motor was activated and the rotating cutter slowly advanced to cut the protruding atherosclerotic lesion and collect the plaque in the collection chamber located at the tip of the catheter. After each pass, the balloon was deflated and either removed or repositioned.

\section{Plaque processing and total RNA extraction}

After atherectomy, half the amount of each plaque was resuspended in $0.5 \mathrm{~mL}$ of $1 \mathrm{X}$ lysis buffer (Applied Biosystems) and $\mathrm{Ca}^{2+}$ and $\mathrm{Mg}^{2+}$-free $\mathrm{IX}$ PBS, and then immediately frozen in liquid nitrogen and stored until use; the second half was processed for cell culturing. The plaques were homogenised in ice-cold blocks using an Ultra Turrax ${ }^{\text {TM }}$ homogeniser for $30 \mathrm{sec}$; glycogen $(20 \mu \mathrm{g} / 500 \mu \mathrm{L})$ was added to the homogenate, which was then processed using the ABI PRISM ${ }^{\circledR} 6100$ platform for total RNA extraction according to the manufacturer's instructions. After extraction, each RNA sample was resuspended in a final volume of $100 \mu \mathrm{L}$ of elution buffer for spectrophotometric yield quantitation. The average amount of RNA was $80 \pm 5 \mathrm{ng} / \mu \mathrm{L}$. 


\section{Cell cultures}

The tissue specimens were washed with IX PBS and the medial tunic, isolated by microdissection under light microscopy, was cut into 1-2 mm pieces. The VSMCs grown from the explants after 10-15 days in Dulbecco's Modified Medium (Gibco) supplemented with $10 \%$ FCS (Gibco) were sub-cultured (a split ratio of $1: 3$ ) and confirmed to be smooth muscle cells by their typical hill and valley morphology and alpha-actin immunofluorescence staining (see In situ RT-PCR section; Skalli et al., 1986). Contamination with endothelial cells was ruled out by negative immunofluorescence staining with an anti-von Willebrand factor VIII antibody. Briefly, cells in Petri-dishes were fixed in absolute methanol at $-20^{\circ} \mathrm{C}$ for 10 min and then incubated for $2 \mathrm{hrs}$ at room temperature with the anti-von Willebrand factor VIII antibody (Sigma, F3520) diluted 1:1000 in 1X PBS. After three washes in $1 X$ PBS at room temperature, the cells were incubated with anti-rabbit IgG-alkaline phosphatase conjugate (Sigma, 10761) diluted 1:500 in Tris buffer, $\mathrm{pH}$ 8.0, and colour developed as described by Engvall and Perlmann (1972).

Confluent VSMCs were resuspended $\left(5 \times 10^{4}\right.$ cells $\mathrm{mL}^{-1}$ ) and plated in T25 flasks (Iwaki) for a total of 25 passages in Dulbecco's Modified Medium (Gibco) and 1\% FCS. Karyotype analyses were made using conventional G-banding techniques. Total RNA was extracted as described above.

\section{Reverse transcription}

One hundred nanograms of total RNA were reversetranscribed using a high-capacity cDNA Archive Kit (Applied Biosystems), random hexamer primers, and the following thermal profile: $25^{\circ} \mathrm{C}$ for $10 \mathrm{~min}, 42^{\circ} \mathrm{C}$ for $1 \mathrm{~h}$, and $95^{\circ} \mathrm{C}$ for $5 \mathrm{~min}$. For all of the further analyses, the cDNA was diluted 1:20 in water.

\section{5' nuclease assays}

The expression of eNOS was screened using the Assays on Demand ${ }^{\text {TM }}$ (Hs00167166_mL) FAM $^{\text {TM }}$ MGB labelled probe.

We always co-amplified the $18 \mathrm{~S}$ reference gene (VIC ${ }^{\mathrm{TM}}$-M GB-labeled probe; 4319413E) with the target gene in the same wells in order to normalise the different amounts of total RNA in the different wells, and their $\mathrm{RT}$ reaction efficiencies.

RT-PCR was performed using the automated ABI Prism $^{\text {TM }}$ 7900HT Sequence Detector System (Applied Biosystems).
The cDNAs were also tested for gDNA contamination, the overall level of which was no more than $0.005 \%$.

\section{Threshold cycle $\left(C_{t}\right)$ and the comparative method $\left(2^{\wedge \Delta \Delta}\right)$}

The different expression was quantitated using the comparative $\mathrm{Ct}$ method (Livak and Schmittgen, 2001). The human heart cDNA pool (Stratagene, PN 735012) was required only as a normalisation step, and many other cDNAs could have been used; the data are expressed as the median fold differences between the SA and ACS plaques.

\section{Data analysis}

The SA and ACS groups were compared by means of one-way ANOVA, followed by Duncan's multiple-range test. Between-group differences were also evaluated using a Student's t-test when appropriate. $p$ values of less than 0.001 were considered statistically significant. The $p$ values of every target gene in each gene panel between the

SA and ACS groups (which were always less than $0.05 \%$ ) support the reliability of the generated data. In order to assess the reproducibility of the method, we calculated the coefficient of variation for each gene, which was never more than $0.67 \%$.

\section{In situ RT-PCR}

The VSMC cultures were prepared in Petri-dishes as described in Cell cultures above, and they were left to adhere directly to glass slides (Applied Biosystems) placed in the growing medium (Dulbecco's Modified Medium supplemented with 10\% FCS, Gibco). Subsequently, after the removal of the medium and two washes in IX PBS, the cells were fixed in $4 \%$ formaldehyde in $1 X$ PBS for 30 min, extensively washed in $1 X$ PBS, permeabilised for $15 \mathrm{~min}$ in $0.5 \%$ Triton X-100 in $1 X$ PBS, and then incubated in TNT $(0.1 \mathrm{M}$ Tris- $\mathrm{HCl}, \mathrm{pH}$ 7.5, $0.15 \mathrm{M} \mathrm{NaCl}, 0.05 \%$ Tween-20) plus 0.5\% blocking reagent (Roche Molecular System) for $20 \mathrm{~min}$. They were then treated with $0.05 \%$ Proteinase $\mathrm{K}$ (Roche Molecular System) in Tris $20 \mathrm{mM}$ and Tween $200.5 \%$ for $30 \mathrm{~min}$ at $37^{\circ} \mathrm{C}$, and transferred to a microwave oven to boil for $30 \mathrm{sec}$.

Invitrogen BAC clones corresponding to the Hs00167166_mL (eNOS) were obtained. The precise position of the probes on chromosome 7 sequences was established by means of a BLAST search of the end of the clone sequences against the 
complete sequence of the chromosomes so that specific primers were designed (sequences available on request) for in situ RT amplification with a J0JOdUTP labelled nucleotide (Molecular Probes) as described by Boniotto et al. (2003), thus giving rise to direct amplicon (550 bp) labelling.

After the in situ PCR, the cells were immunostained with anti-VSMC antibody (A5228 SigmaGenosys, against smooth muscle-specific $\alpha$-actin) and anti-mouse FITC-labelled antibody (DAKO) according to the manufacturers' instructions. The cells were counterstained with DAPI $(0.010$ $\mathrm{mg} / \mathrm{mL}$ ) for $10 \mathrm{~min}$ at room temperature and rinsed with IX PBS. The analyses were made as described by Tearney et al., (2003).

The slides were directly analysed under an epifluorescence microscope (Olympus Provis) equipped with a thermoelectronically cooled, charged-coupled camera (Photometrics CH350). Smooth muscle cell actin was immunohistochemically quantified by means of computer-assisted colour image analysis (BIOQUANT, R\&M Biometrics). A colour threshold mask for the number of positive cells was established, and the positive areas were expressed as percentages of the total analysed area.

\section{Nitric oxide synthase activity}

NOS activity in the cultured cells was determined by measuring the conversion of $\mathrm{L}-(3 \mathrm{H})$-arginine into $\mathrm{L}$ (3H)-citrulline as described by Trovati et al., (1999). Briefly, confluent VSMCs were washed with HEPES$\mathrm{CaCl}^{2}$ buffer $\left(\mathrm{pH} 7.4,37^{\circ} \mathrm{C}\right)$ and incubated for $15 \mathrm{~min}$ at $37^{\circ} \mathrm{C}$ in $1 \mathrm{~mL}$ of the same buffer. $\mathrm{L}-(3 \mathrm{H})$-arginine (Amersham) $185 \times 10^{3} \mathrm{~Bq}(5 \mu \mathrm{Ci})$ was then added to each dish and, after $1 \mathrm{~min}$, the cells were stimulated with $2 \mu \mathrm{mol} / \mathrm{l}$ ionomycin (Roche Molecular System). After $10 \mathrm{~min}$ incubation at $37^{\circ} \mathrm{C}, 2 \mathrm{ml}$ of cold PBS containing $5 \mathrm{mmol} / \mathrm{L} \mathrm{L}$-arginine and $4 \mathrm{mmol} / \mathrm{I} \mathrm{EDTA}$ were added to the dishes to stop the reaction. Ethanol $(0.4 \mathrm{~mL}, 96 \%)$ was then added to each well and, after evaporation, $2 \mathrm{~mL}$ of $20 \mathrm{mmol} / \mathrm{L}$ HEPES-Na $(\mathrm{pH} 6)$ were added. The supernatants were collected, applied to $2 \mathrm{~mL}$ columns of Dowex AGWX8-200 (Aldrich) to trap radioactive arginine, and $4 \mathrm{~mL} \mathrm{H}_{2} \mathrm{O}$ was used to elute radioactive citrulline. The radioactivity of the eluate was then measured by means of liquid scintillation counting.

\section{Chemicals}

Unless otherwise specified, all of chemicals were supplied by Sigma.
Table 1. eNOS mRNA expression levels screened in ex vivo plaques from SA and ACS patients, and in vitro cultured VSMCs at passage 1, 10 and 25 after explantation. The numbers indicate fold differences with a $p<0.001$.

\begin{tabular}{lll}
\hline \hline Specimens & ACS & SA \\
\hline Plaques ex vivo & 642 & 45 \\
VSMC 1 & 638 & 43 \\
VSMC 10 & 639 & 46 \\
VSMC 25 & 640 & 44 \\
\hline
\end{tabular}

\section{Synoptic list of abbreviations}

In situ RT-PCR = in situ reverse-transcription polymerase chain reaction; FAM and VIC are trade marks; MGB = minor groove binder; ST is an electrocardiographic segment.

\section{Results}

\section{Gene expression}

The 30 coronary plaque samples were collected from 15 SA and 15 ACS patients, and were also used to obtain specific VSMC cultures. Table 1 shows the expression of the eNOS gene, which was significantly higher $(p<0.001)$ in the ACS plaques and plaque-derived cell cultures even after 25 platings.

\section{VSMC morphology}

The VSMCs derived from the SA plaques showed a more marked hill and valley morphology than the ACS plaques (Figure $1 \mathrm{a}$; the white dotted lines indicate the two different patterns), as has previously been observed by Skalli et al., (1986). Karyotype analyses were made at plating stages 0, 10 and 25 with no changes in the chromosome number and morphology (data not shown). Figures $1 b, 1 c$ and Id show the VSMCs cultured from ACS plaques at passages 0, 10 and 25: no substantial morphological changes from the cobblestone-like shape (Frid et al., 1997) were detectable.

\section{In situ PCR and immunohistochemistry}

Given the 5'-nuclease assay results obtained from whole plaques, we visualised the differentially expressed mRNAs in the VSMC lineages from SA and ACS plaques in order to confirm the real expression of eNOS mRNAs. This was done by means of an in situ RT-PCR followed by an immunohistochemistry reaction.

The total number of VSMCs showing $\alpha$-actin and eNOS signals was also counted. Figure 2 a shows 

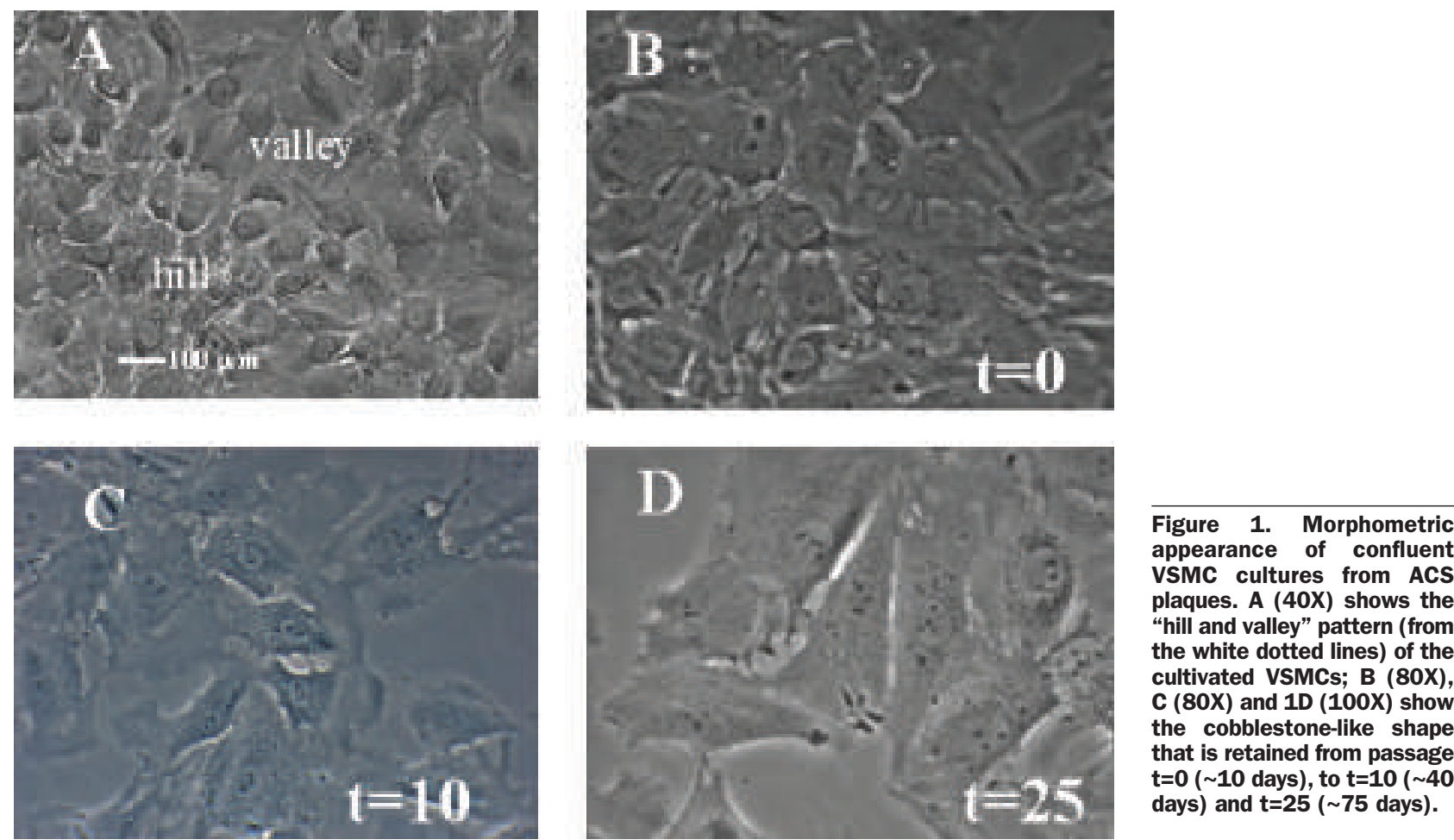

the double labelling for the co-localisation of VSMCs and mRNAs as revealed by immunocytochemistry reactions using Genosys antibodies (green fibres) and in situ $\mathrm{RT}-\mathrm{PCR}$ reactions to eNOS mRNA (purple grains). To provide quantitative data based on the specific over- or underexpression of the gene, Figure $2 \mathrm{~b}$ shows the average

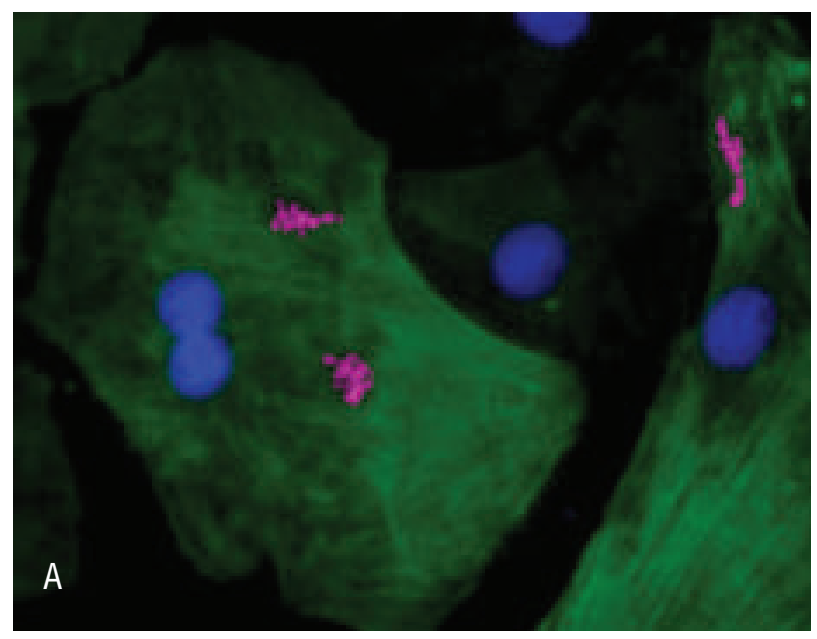

Figure 2. A) In situ RT-PCR showing eNOS mRNAs (JOJO; purple grains) followed by immunocytochemistry reactions to VSMC ( $\alpha$-actin) with FITC-labelled antibodies (green fibres) in cultivated VSMCs from ACS plaques. The nuclei are DAPI counterstained (blue). B) shows the average cell counts: the $y$-axis represents the total cell number, the white blocks the counted number of cultivated VSMCs, and the black blocks the subfraction of VSMCs expressing eNOS and their percentages. cell counts (roughly $9000 \alpha$-actin positive cells): the $y$-axis represents the total cell number of $\alpha$ actin positive cells, the white blocks the number of v-SMCs ( $1620 \pm 20$ in SA and $4400 \pm 32$ in ACS plaques), and the black blocks the subfraction of $\alpha$ actin positive VSMCs expressing eNOS $(518 \pm 12$ in SA and $3652 \pm 18$ in ACS plaques) and per-

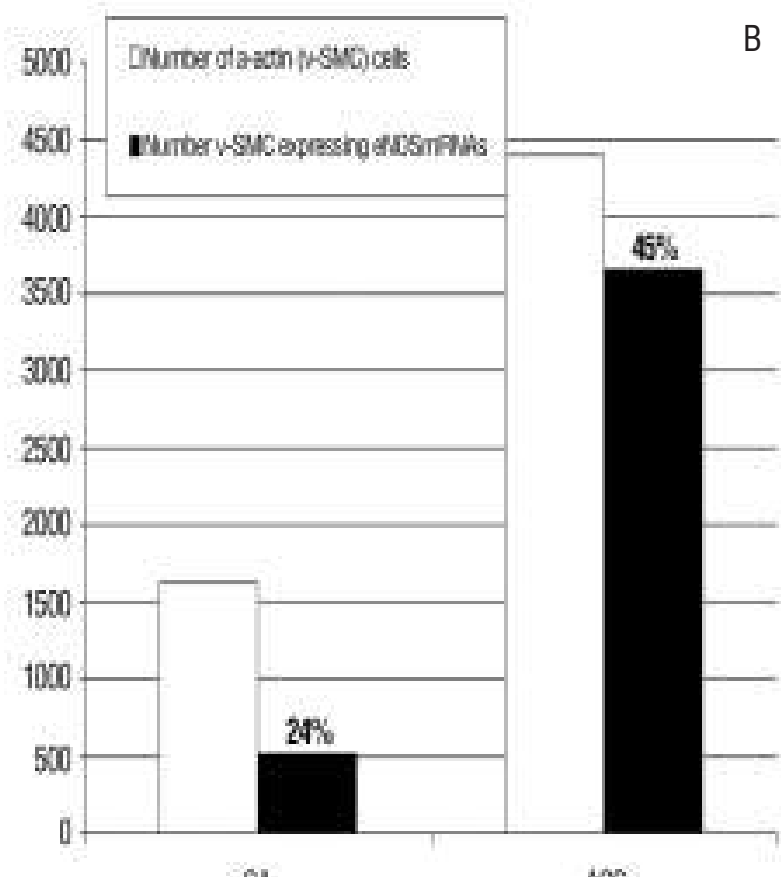

Sh ACS 
centage values (respectively $24 \%$ and $45 \%$ ). Fewer than $2 \%$ of the cells were negative to $\alpha$ actin staining and did not express eNOS mRNA.

\section{Citrulline synthesis in ACS and SA VSMC cultures}

As shown in Figure 3, baseline $L-\left[{ }^{3} \mathrm{H}\right]$ citrulline production from $L-\left[{ }^{3} \mathrm{H}\right]$ arginine in the VSMCs cultured from ACS plaques was $0.052 \pm 0.004$ pmoles/min/mg total protein, which was significantly more than the conversion rate of $0.025 \pm 0.002$ pmoles/min/mg total protein observed in the VSMCs cultured from SA plaques $(p<0.001)$. Ionomycin rapidly and significantly increased $L-\left[{ }^{3} \mathrm{H}\right]$ citrulline production from $L-\left[{ }^{3} \mathrm{H}\right]$ arginine to respectively $0.38 \pm 0.04$ and $0.18 \pm 0.02 \mathrm{pmoles} / \mathrm{min} / \mathrm{mg}$ total protein, but the difference in NOS activity between the ACS and SA VSMCs remained significant $(p<0.0001)$.

\section{Discussion}

The aim of this study was to compare the phenotypic characteristics and eNOS expression and activity in atherosclerotic coronary plaques obtained from patients with SA and ACS, as well as in cultured VSMCs derived from the same plaques. The results show that the VSMCs from SA and ACS plaques have different biochemical phenotypes, and that ACS plaques are associated with increased eNOS expression.

Our primary finding is that the plaques from ACS patients showed a statistically significant increase in the transcription of eNOS gene.

More intriguing, the gene expression results demonstrate that atherosclerotic mechanisms in cells directly involved in atherosclerotic plaque formation and development (such as VSMCs) may induce cell dedifferentiation, which persists in culture and is associated with differences in eNOS expression. The latter finding suggests that cell cultures derived from atherosclerotic plaques could be used as models for more detailed in vitro studies of the biochemical and molecular characteristics of the plaques from which the cells originated.

Our VSMCs obtained ex vivo from atherosclerotic plaques maintained their original phenotype, which we defined on the basis of cell and culture morphology, eNOS gene expression patterns, and arginine/citrulline conversion. As far as cell morphology is concerned, the ACS plaque cultures prevalently contained cells with a cobblestone-like

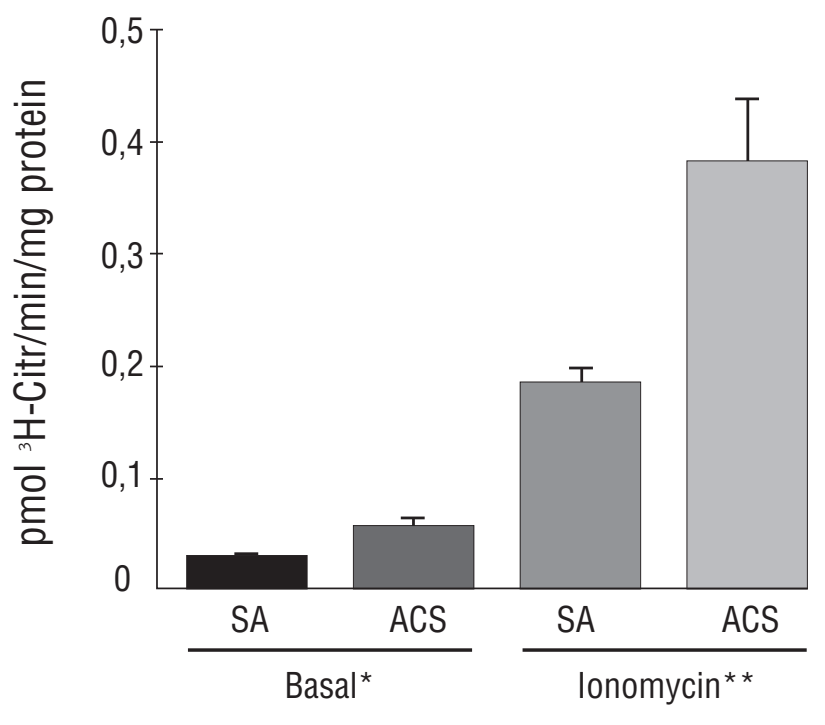

Figure 3. eNOS activity in SA and ACS VSMCs under baseline conditions (left) and after the addition of ionomycin (right; ${ }^{*} p<0.01$, ACS vs SA; ${ }^{*} p<0.001$, ACS vs SA) measured using the $\mathrm{L}-\left[{ }^{3} \mathrm{H}\right]$ arginine/L-[ $\left.{ }^{3} \mathrm{H}\right]$ citrulline conversion.

shape, whereas the cells in the SA cultures were more spindle-shaped. Furthermore, the SA cultures showed the hill and valley configuration typical of VSMC cultures; this was less evident in the ACS cultures, which developed multiple layers of densely mixed cells. These findings are consistent with those reported by Faries et al. (2001) suggesting less controlled cell cycling and growth in ACS plaques. Moreover, as suggested by Frid et al. (1997), diamond-like VSMCs are more prone to phenotypic modulation and growth activation.

The differences in eNOS expression patterns were retained in the SA and ACS plaques throughout all culture passages, thus supporting the evidence of altered and committed genetic programming before plaque sampling. The differences in the abundance of mRNA also correlate well with protein activity because the $L-\left[{ }^{3} \mathrm{H}\right]$ arginine/ $L-\left[{ }^{3} \mathrm{H}\right]$ citrulline conversion rate was higher in the VSMCs derived from ACS plaques.

The association between cell dedifferentiation and altered NO synthetic pathways in cells from patients with ACS and SA is one of the mechanisms responsible for unstable angina and myocardial infarction. In particular, it supports the hypothesis that in acute coronary syndromes caused by such plaques, which are also intrinsically more unstable (enhanced in vivo thrombosis and inflammatory processes), the increased expression of eNOS from VSMC cells may be a protective response against the sudden expansion of an atheromatous lesion. 
The results of this study confirm previous information concerning transcription differences in the NOS gene family (Michel and Feron, 1997): eNOS activity may be regulated by epigenetic factors (i.e. methylation) and may be one of the pathways that are differentially expressed in ACS and SA plaques in vivo. Such strong differences are also maintained in in vitro VSMC cultures derived from different atherosclerotic plaques, which could therefore provide researchers with new models for biochemistry and cell biology studies aimed at improving our understanding of the processes that selectively contribute to the pathogenesis of cardiovascular disease.

\section{Acknowledgements}

The authors would like to thank L. Gentile, V. Sebastiano, A. Esposito, V. Merico and M. Monti at the Open Lab (University of Pavia) for their technical assistance. This work was partially granted by Associazione Aterosclerosi e Trombosi.

\section{References}

Bochaton-Piallat ML, Ropraz P, Gabbiani F, Gabbiani G. Phenotypic heterogeneity in rat smooth muscle cell clones. Arterioscl. Throm. Vas 1996;16:815-20.

Boniotto M, Radillo 0, Braida L, Pirulli D, Citta A, Not T, Amoroso A, Crovella $S$. Detection of $M B L-2$ gene expression in intestinal biopsies of celiac patients by in situ reverse transcription polymerase chain reaction. Eur j Histochem 2003;47:177-80.

Cheng GC, Loree HM, Kamm RD. Distribution of circumferential stress in ruptured and stable atherosclerotic lesions. Circulation 1993;87:1179-87.

Davies MJ, Thomas AC. Plaque fissuring: the cause of acute myocardial infarction, sudden ischaemic death, and crescendo angina. $\mathrm{Br}$ Heart J 1985;53:363-73.

De Graaf JC, Banga JD, Moncada S. Nitric oxide functions as an inhibitor of platelet adhesion under flow conditions. Circulation 1992;85:2284-90.

Engvall E, Perlmann P. Enzyme-linked immunosorbent assay, Elisa. 3. Quantitation of specific antibodies by enzyme-labeled antiimmunoglobulin in antigen-coated tubes. J Immunol 1972;109: 129-35.

Faries PL, Rohan DI, Takahara H. Human vascular smooth muscle cells of diabetic origin exhibit increased proliferation, adhesion, and migration. J.Vasc Surg 2001;33:601-7.

Frid MG, Moiseeva EP, Stenmark KR. Multiple phenotypically distinct smooth muscle cell population exist in the adult and developing bovine pulmonary arterial media in vivo. Circ Res 1994;75:669-81.

Frid MG, Moiseeva EP, Stenmark KR. Smooth muscle cells isolated from discrete compartments of the mature vascular media exhibit unique phenotypes and distinct growth capabilities. Circ Res 1997;81:940-52.

Fuster $\mathrm{V}$, Badimon $\mathrm{L}$, Badimon J. The pathogenesis of coronary artery disease and the acute coronary syndromes. $N$ Engl J Med 1992;326:242-50.

Gauthier TW, Scalia R, Murohara T. Nitric oxide protects against leukocyte-endothelium interactions in the early stages of hypercholesterolemia. Arterioscl Throm Vas 1995;15:1652-9.

Ko YS, Yeh HI, Haw M. Different expression of connexin43 and desmin defines two subpopulation of medial smooth muscle cell in human internal mammary artery. Arterioscl Throm Vas 1999;19:1669-80.

Kohchi K, Takebayashi S, Hiraki T. Significance of adventitial inflam- mation of the coronary artery in patients with unstable angina: results at autopsy. Circulation 1985;4:709-16.

Kuro-o M, Nagai R, Nakahara K. cDNA cloning of a myosin heavy chain isoform in embryonic smooth muscle and its expression during vascular development and arteriosclerosis. J Biol Chem 1991;266:3768-73.

Leach IH, Blundell JW, Rowley JM. Acute ischaemic lesions in death due to ischaemic heart disease. An autopsy study of 333 cases of out-of-hospital death. Eur Heart J 1995;16:1181-5.

Livak KJ, Schmittgen DT. Analysis of relative gene expression data using Real Time Quantitative PCR and the $2^{\wedge-\Delta \Delta} \mathrm{Ct}$ Method. Methods 2001;25:402-8.

Luoma JS, Stralin $P$, Marklund SL, Hiltunen TP, Sarkioja T, YlaHerttuala S. Expression of extracellular SOD and iNOS in macrophages and smooth muscle cells in human and rabbit atherosclerotic lesions. Arterioscl Throm Vas 1998;18:157-67.

Michel T, Feron 0. Perspective series: Nitric oxide and nitric oxide synthase. J Clin Invest 1997;9:2146-52.

Moncada S, Higgs A. The L-arginine-nitric oxide pathway. N Engl J Med 1993;329:2002-12.

Mosse PR, Campbell GR, Wang ZL, Campbell YH. Smooth muscle phenotypic expression in human carotid arteries. I: comparison of cells with diffuse intimal thickenings adjacent to atheromatous plaques with those of the media. Lab Invest 1985;53:556-62.

Owens GK. Regulation of differentiation of vascular smooth muscle cells. Physiol. Rev 1985;75:487-517.

Papapetropoulos A, Rudic RD, Sessa WC. Molecular control of nitric oxide synthases in the cardiovascular system. Cardiovasc. Res, 1999;43:509-20.

Richardson PD, Davies MJ,Born GVR. Influence of plaque configuration and stress distribution on fissuring of coronary atherosclerotic plaques. Lancet 1989;2:941-4.

Rocnik E, Saward L, Pickering JG. HSP47 expression by smooth muscle cells is increased during arterial development and lesion formation is inhibited by fibrillar collagen. Arterioscl. Throm. Vas 2001; 21:40-6.

Szmitko PE, Wang CH, Weisel RD, Jeffries GA, Anderson TJ, Verma S. Biomarkers of vascular disease linking inflammation to endothelial activation. Circulation 2003;108:2041-8.

Skalli 0, Ropraz P, Trzeciak A, Benzonana G, Gillessen D, Gabbiani G. A monoclonal antibody against alfa- smooth muscle actin: a new probe for smooth muscle differentiation. J Cell Biol 1986;103: 2787-96.

Tearney JG, Yabushita H, Houser SL, Aretz HT, Jang IK, Schlendorf $\mathrm{KH}$, et. al. Quantification of macrophage content in atherosclerotic plaques by optical coherence tomography. Circulation 2003;107:113-9.

Trovati M, Massucco P, Mattiello L. Human vascular smooth muscle cells express a constitutive nitric oxide synthase that insulin rapidly activates, thus increasing guanosine $3^{\prime}: 5^{\prime}$-cyclic monophosphate and adenosine $3^{\prime}: 5^{\prime}$-cyclic monophosphate concentrations. Diabetologia 1999;42:831-9.

Van der Wal AC, Becker AE, Van Der Loos CM. Site of intimal rupture or erosion of thrombosed coronary atherosclerotic plaques is characterized by an inflammatory process irrespective of the dominant plaque morphology. Circulation 1994;89:36-44. 